Research Article

\title{
Aging and the Art of Happiness: Time Effects of A Positive Psychology Program with Older Adults
}

Elizabeth Orsega-Smith ${ }^{*}{ }^{\dagger}$, Stephen Goodwin ${ }^{\dagger}$, Melissa Ziegler, Katie Greenawalt, Jennie Turner, Erica Rathie

Department of Behavioral Health \& Nutrition, Carpenter Sports Building, Newark, Delaware, University of Delaware, United States of America; E-Mails: eosmith@udel.edu; goody@udel.edu; Mlz@udel.edu; kgreenaw@udel.edu; ilturner@udel.edu; ejrathie@udel.edu

$\dagger$ These authors contributed equally to this work.

* Correspondence: Elizabeth Orsega-Smith; E-Mail: eosmith@udel.edu

Academic Editor: Lisa Hollis-Sawyer

Special Issue: Got Aging? Examining Later-life Development from a Positive Aging Perspective

OBM Geriatrics

2019, volume 3, issue 1

doi:10.21926/obm.geriatr.1901029
Received: October 31, 2018

Accepted: January 07, 2019

Published: January 10, 2019

\begin{abstract}
Background: Research has shown that positive psychology interventions can enhance subjective well-being and reduce depression. However, the efficacy of these programs with older adult populations has been minimally studied. The present study studied the short and long term impact of an intervention enhancing happiness and overall mental well-being in older adults.

Methods: The Art of Happiness is an 8-week program conducted at 2 senior centers in the state of Delaware. Each 90-minute class examined a different topic; (1) defining happiness, (2) stress management, (3) reflecting on happiness, (4) compassion and human connection, (5) forgiveness, (6) transforming suffering, (7) mindfulness, and (8) humor. Pre, post, and 6 months post program questionnaires assessed participant subjective happiness, stress, life satisfaction, depression, mindfulness, arousal states, and general demographic and health information.
\end{abstract}

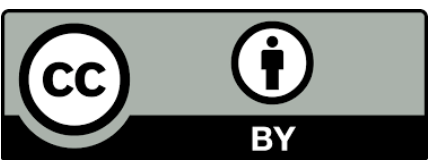

(C) 2019 by the author. This is an open access article distributed under the conditions of the Creative Commons by Attribution License, which permits unrestricted use, distribution, and reproduction in any medium or format, provided the original work is correctly cited. 
Results: 32 participants completed the course and were mostly married (43.8\%), female (87.5\%) and Caucasian (90.6\%), with an age range of 53-84 years (70.91 +.70 years). After controlling for age, gender, and health issues, there was a significant time effect over 6 months post program for happiness, mood state of tiredness, and mindfulness constructs of non-judging and non-reactivity, stress, and satisfaction with life $(p<.05)$. Conclusions: These results suggest that changes in positive mental health have the potential to be maintained in older adults after a positive psychology program ends. It may be that individuals have learned techniques and incorporated them into their lifestyle. Programs emphasizing these aspects of well-being may have potential to buffer the older adult population against poor mental health by improving subjective happiness and mental wellbeing.

\section{Keywords}

Aging; happiness; well-being; positive psychology

\section{Introduction}

The Dalai Lama has stated that the purpose of every human being is to seek happiness. Further, the Dalai Lama believes it is possible to train one's mind to develop those traits that lead to greater happiness. In order to achieve happiness the Buddhist philosophy teaches us that compassion for others, forgiveness, and perspective are central to any happy and fulfilling life. This attitude is also reflected in our western philosophy as almost every parent will express one of their main goals is for their child to be happy [1].

Lyubomirsky [2] has stated $50 \%$ of our happiness is due to genetics, $10 \%$ to our life circumstances, but $40 \%$ is within our control. What we do with that $40 \%$ can have a significant impact on our overall happiness. With that in mind we wanted to examine if we could see any long-term effects on the happiness of older adults after participating in an 8-week course. The course was based upon the teachings of the Dalai Lama as well as positive psychology developed by Dr. Martin Seligman and Dr. Mihaly Csikszentmihalyi. A previous study had shown these lessons had immediate positive effects on the happiness of older adults [3]. The purpose of this study was to see if those initial gains would still be apparent 6 months post intervention.

With approximately 46.2 million Americans currently over the age of 65 , older adults currently represent $14.5 \%$ of the United States population [4]. Furthermore, by 2030, older adults will comprise $20 \%$ of the population and by 2050 , the number of Americans aged 65 and older will more than double its current number [4, 5]. As this population suffers from multiple declines in functional abilities and independence, aging is often characterized as a time of loss [6]. Cognitive ability, mental well-being, and physical functioning, all may decline throughout the aging process $[7,8]$. Additionally, chronic diseases which often plague older adults leading to psychological health outcomes $[9,10]$ can result in decreased overall quality of life and sense of well-being and in the older adult population [11].

As the United States population ages, there is an increased demand for mental and behavioral health services. Furthermore, 15 to 20 percent of U.S. adults older than age 65 have experienced 
depression [5, 12]. Depression is not only correlated with increased risk of morbidity, but also a heightened risk of suicide, and declines in physical, cognitive, and social functioning, all of which can lead to increased mortality [13].

Evidence-based health promotion programs targeting older adults are well established, although programming focused on mental health promotion is lacking [14]. The focus of previous evidenced based mental health interventions for older adults have been on those who have been diagnosed with severe depression or dysthymia, are chronically ill, or are home bound under the care of social services. Four evidence-based mental health programs; Healthy IDEAS (Identifying Depression, Empowering Activities for Seniors), PEARLS (Programs to Encourage Active, Rewarding Lives), and IMPACT (Improving Mood-Promoting Access to Collaborative Treatment) program; have been recommended on the National Council on Aging website. Overall, the focus of these programs is to connect frail older adults who are home-bound or clinically depressed, or their care providers to services to assist in improving their quality of life. These programs highlight managing depression or other negative mental health disorders through education of ways to avoid substance abuse or promotion of services and treatment.

Although age related declines may occur, positive traits and characteristics attained through life experience may be protective against mental illness as well as increase positive mental wellbeing in older adults [15-18]. However, we can look to incorporate positive psychological characteristics into programs and treatments to impact aging process. There is some evidence that positive psychology interventions can promote well-being in older adults. In a recent review of positive psychology interventions and older adults, Sutipan and colleagues [18] found that reminiscing seemed to have the greatest effect on quality of life. However, there is no conclusion about a set intervention length or specific types of activities that make the most impact in this population.

Positive psychology is defined as the scientific study of positive experiences and positive individual traits. This concept stems from the belief that human strengths and virtues may act as buffers against mental illness [16, 19]. This discipline emphasizes prevention of illness by fostering positive emotions extending beyond the focus of clinical psychology that may focus on treatment of mental illness to alleviate suffering [16]. Previous research has concluded that positive psychology interventions can develop overall well-being through enhancements in subjective wellbeing, psychological well-being, and happiness and reduce depressive symptoms and negative affect $[21,22]$. While research in the field of positive psychology is growing, few studies have specifically targeted the older adult population; those that have, showed promising results. In a longitudinal study, optimism has predicted lower risk of stroke [23] and participation in positive psychology programs has shown reduction in depressive symptoms and improvements in life satisfaction [17, 24]. In order to foster positive aging and mental well-being in older adult populations further research is suggested.

One particular aspect of positive mental well-being involves the concept of happiness. Happiness can be described as "the experience of joy, contentment, or positive well-being, combined with a sense that one's life is good, meaningful, and worthwhile" [2]. Research in the field of positive psychology and happiness often define a happy person as someone who experiences frequent positive emotions like joy, interest, and pride, and infrequent (though not absent) negative emotions such as sadness, anxiety, and anger. Often, happiness is used 
interchangeably with subjective well-being, and has also been said to be closely related to life satisfaction, appreciation of life, and moments of pleasure [25].

Multiple studies have found that happiness and health go hand-in-hand. Research has found that happiness can improve heart health [26, 27], enhance the immune system [28], reduce disease and disability [29], increase longevity [30,31], and can alleviate pain in the context of disease [32]. Happiness and positive emotions can have a protective effect on health.

Mindfulness is another aspect of positive mental health and can be defined as being in the moment, having non-judgmental awareness, and being non-reactive and non-judgmental [33]. As a practice, mindfulness has been around for many years, but researchers have only recently begun to study its effect on health and well-being. Studies have shown that in older adults mindfulness training can decrease anxiety, improve depressive symptoms [34], improve sleep, reduce pain, and improve well-being [35]. Not only can mindfulness help an individual reach an inner peace but can also bring about changes in mental health, physical pain, and overall happiness resulting in positive effect on older adults.

Another construct that has been shown to have a significant impact on one's happiness is forgiveness. While we did not measure forgiveness it was an important topic discussed in the course. According to the Greater Good Science Center at UC Berkely [36], those who are able to forgive others have more happiness and more positive health outcomes. Forgiveness is significant in that when one is able to forgive another person it allows them to move on with their life and in some cases rebuild a relationship. Since having strong relationships with others is one of the strongest indicators of happiness [37] the ability to forgive and move on is crucial to many people's happiness.

The concept of mood is multifaceted and challenging to define. In the domain of cognitive psychology, mood results from the appraisal of an emotion, and is thought of as a collection of enduring feelings related to evaluative and cognitive states, which effect all subsequent evaluations, feelings, and actions [38]. Mood has been defined and measured in the literature in terms of positive and negative affect. Positive and negative affect can each be described in terms of bipolar "poles", for example, adjectives describing positive affect such as "active," "energetic," and "lively" represent the high pole, while items like "tired," "sleepy," and "sluggish" represent the low pole [39]. Positive affect can be defined as pleasurable engagement with the environment resulting in happiness, joy, excitement, enthusiasm, and contentment [40]. Individuals who score high in positive affect are more likely to describe themselves as enthusiastic, confident, and motivated than people who score low in positive affect [41]. Happy people have skills and resources that they have acquired over time while experiencing positive moods, making success again more likely [25]. Hence, positive affect or positive mood is associated with accomplishments and overall happiness.

According to Martin Seligman, well-being is the basis for positive psychology, a construct required for personal flourishment. Well-being as a construct is operationalized by five measurable concepts: (1) positive emotion (2) engagement (3) meaning (4) positive relationships and (5) accomplishments (PERMA) [42]. Positive emotions are an individual's subjective views on his or her life, and are often measured by life satisfaction. Engagement is the subjective experience of flow state. In flow, an individual becomes absorbed in their task entirely, time seemingly stops or slows and cognitive thought is absent. Meaning is conceptualized by the notion that one is serving something greater than oneself (a higher purpose). Accomplishment is defined 
by the pursuit of success, achievement and/or mastery for one's own personal gain. Positive relationships are the pursuit of meaningful, healthy relationships in one's life. Together, these five elements provide support for personal well-being [42]. PERMA has previously been utilized in positive psychology research, however a lack of experimental application among older adults in the United States warrants further investigation [24]. The Art of Happiness program development was guided by the five measurable concepts of PERMA and the teachings of the Dalai Lama. As the principles of Positive Psychology and those espoused by the Dalai Lama are similar in many respects the course easily blends the science of happiness with the Buddhist philosophy. Martin Seligman's theory of well-being and the 5 concepts has guided our "Art of Happiness" curriculum development.

We were interested in studying the impact of participation in a course based on positive psychology. Our research question was: What is the effect of time (pre-post- 6 months after intervention) controlling for age, gender and health conditions on outcomes of happiness, mindfulness, mood, depression, stress, and satisfaction with life in a population participating in an 8 week positive psychology program.

\section{Materials and Methods}

\subsection{Participants}

Participants were recruited from two local senior centers via word of mouth and distribution of flyers at the centers. Convenience sampling was used to gain participants. A week prior to program implementation, researchers attended three popular senior center events in order to promote the Art of Happiness program. Program participant inclusion criteria included the following: (1) participants were required to be 50 years of age and older, (2) be community dwelling residents, (3) be independently living (without the reliance on another individual to assist with the day to day activities), (4) have the ability to ambulate, (5) could commit to attending the 8 weekly sessions (6) have no severe cognitive impairment (as per self report), (7) no current clinically diagnosed depression, and (8) not reliant on a caregiver. There was no restriction on class size. Participants who completed the pre and post questionnaires and met the minimum requirements of attending six out of the eight classes received a \$25.00 Visa gift card.

A total of 34 participants agreed to participate and completed the pre and post intervention assessment with a mean age of $70.9 \pm 7.7$ years. The majority of the participants were female (85.3\%), Caucasian (91.2\%), who were mostly married (47.1\%) with some education beyond a high school degree (53.0\%). Over $70 \%$ self-reported that they had high cholesterol or hypertension (Table 1). Due to attrition, not all participants completed assessments at the 6 month follow-up.

The study was approved by the University of Delaware's Institutional Review Board on January, 2016. Prior to beginning the program, all participants were given an informed consent agreement which was then signed. 
Table 1 Descriptive statistics of intervention participants at baseline.

\begin{tabular}{|l|l|}
\hline & Intervention ( $n=34)$ \\
\hline Age, years (mean \pm SD) & $70.91 \pm 7.70$ \\
\hline Sex, \%(n) & $85.3(29)$ \\
Female & $14.7(5)$ \\
Male & \\
\hline Race/Ethnicity, \%(n) & $91.2(31)$ \\
Caucasian & $8.8(3)$ \\
African American & \\
\hline Marital Status, \%(n) & $17.6(6)$ \\
Single & $47.1(16)$ \\
Married & $14.7(5)$ \\
Separated/divorced & $20.6(7)$ \\
Widowed & \\
\hline Highest Level of Education, \%(n) & $44.1(15)$ \\
High school diploma or less & $17.6(6)$ \\
Some college/did not graduate & $11.8(4)$ \\
Technical/vocational school & $17.7(6)$ \\
Associates/bachelor's degree & $5.9(2)$ \\
Graduate school & $2.9(1)$ \\
Other & $51.6(16) n=31$ \\
\hline Health Problems, \%(n) & $18.5(5) n=27$ \\
Overweight/obese & $70.0(21) n=30$ \\
Diabetes & $77.4(24) n=31$ \\
Hypertension & $55.2(16) n=29$ \\
High Cholesterol & \\
Other & \\
\hline
\end{tabular}

\subsection{Measures}

\subsubsection{Demographics}

Participants' demographic information related to gender, age, education level, marital status, ethnicity, and health status was collected. In terms of health information, participants reported if they had ever been told by a doctor they were overweight or obese, had diabetes, had hypertension, had high cholesterol, or had any other illness.

\subsubsection{Subjective Happiness}

The 4 item Subjective Happiness Scale [43] was used to assess subjective happiness. Participants choose one of 7 options such as "In general, I consider myself" (1=not a very happy person, $7=$ a very happy person) or "Some people are generally not very happy. Although they are not depressed, they seem as happy as they might be. To what extent does this characterization 
describe you" (1=not at all, 7=a great deal). The 4 items are summed to create an indicator of level of overall happiness.

\subsubsection{Mindfulness}

Mindfulness was measured using the Five Facet Mindfulness Questionnaire [44]. Thirty-nine items measured 5 components of mindfulness; non-judge, describe, non-react, observe, and act with awareness. Participants respond to the statements using a 5 point Likert scale where $1=$ never or very rarely true and 5= very often or always true. Example items for the subscales are as follows: observe "I notice smells and aromas of things." Describe: "My natural tendency is to put my experiences into words." Act with awareness: "I find myself doing things without paying attention." Non-judge: "I criticize myself for having irrational or inappropriate emotions." Non-react: "When I have distressing thoughts or images, I feel calm soon after." Negatively worded items are reverse scored. A sum of the items is calculated for each subscale. High levels of each specific mindfulness subscale are considered by high scores on each subscale.

\subsubsection{Satisfaction with Life}

The Diener Satisfaction with Life Scale [45] assessed satisfaction with life (SWL). In this 5 item scale participants respond on a 7 point Likert Scale where 1= strongly disagree and $7=$ strongly agree. Example statements include "If I could live my life over, I would change almost nothing", "The conditions of my life are excellent", or "'In most ways my life is ideal". The 5 items are summed and the score indicates one's satisfaction with their life overall. Alpha coefficients have ranged from .79-.87 [46].

\subsubsection{Mood}

To measure mood states, the Activation Deactivation Checklist $[47,48]$ was used. Participants respond to states using a 4 point scale from "definitely feel" to "definitely do not feel". The 4 subscales are: Tired (sleepy, wide-awake, drowsy, wakeful, tired,); Calmness (placid, calm, at-rest, still, quiet); Energetic (active, vigorous, energetic, lively, full-of-pep); and Tension (fearful, jittery, clutched-up, intense, tense); which have been validated via factor analysis [48]. After reverse scoring items, total sum of items for each subscale are calculated.

\subsubsection{Perceived Stress}

Stress was assessed by the 10 item Perceived Stress Scale (PSS) [49]. Participants are presented with potential life situations that they may have encountered over the past month and asked about their thoughts and feelings pertaining to them. Participants respond to how these events are perceived as stressful with a 5 point Likert scale where $0=$ "Never" and 4= "Very often". Example situations include "felt nervous or stressed", "felt that you were on top of things", and "been upset because of something that happened unexpectedly". After reverse scoring some of the positively worded items, and then summing all 10 items, high scores are indicators of high stress. Chronbach alpha has been reported as $>.70$ [50]. 


\subsubsection{Depression}

Depression was assessed by the Patient Health Questionnaire (PhQ-9) [51]. Participants were asked to assess how frequently in the past two weeks they have been experiencing symptoms in 9 different scenarios. Responses were on a 4 point scale from $0=$ not at all and $3=$ nearly every day. Example scenarios are "Feeling tired or having little energy", "Feeling bad about yourself - or that you're a failure or have let yourself or your family down", "Little interest or pleasure in doing things", and "Feeling down, depressed or hopeless". Based on a sum score, minor depression is referred as a score of 10-14, moderate 15-19 and major depression, severe $>20$ [52].

\subsection{Procedures}

The Art of Happiness is an 8-week program guided by Seligman's PERMA principles and using concepts taught by the Dalai Lama with the goals of enhancing happiness levels and overall mental well-being in older adults. This program implemented at 2 senior centers. The program consisted of once per week 90 minute classes that examined a different weekly topic including; (1) defining happiness, (2) stress management, (3) reflecting on happiness, (4) compassion and human connection, (5) forgiveness, (6) transforming suffering, (7) mindfulness, and (8) humor [2]. Each class session incorporated didactic material via lecture, discussion on homework assignments and readings, and class activities. Participants used the homework activity as a means to reflect on the topic of the week. For example, following the introduction on happiness, participants were asked to complete three unselfish acts of kindness each day for three different people. Similarly, following the lecture on compassion, participants were asked to write down three things for which they were grateful. "The Art of Happiness: A Handbook for Living," 10th anniversary edition by the Dalai Lama and Howard C. Cutler was given to each participant along with a folder for hand-outs and a journal to utilize for homework reflections and class notes. Because weekly homework reflections were not collected, each participant determined the level of disclosure of their thoughts during class discussions. The researchers did not collect these participant journals. Each participant received a handout containing weekly lecture points to take home at the conclusion of every class session. See Table 2 for a week-by-week summary of the intervention. This was previously pilot tested [2] and we then expanded this project.

Table 2 Weekly Intervention Description.

\begin{tabular}{|l|l|l|l|}
\hline & Theme & Purpose & Week \\
\hline 1 & $\begin{array}{l}\text { Introduction } \\
\text { to happiness }\end{array}$ & $\begin{array}{l}\text { Introductions, class } \\
\text { structure, and define } \\
\text { happiness. }\end{array}$ & $\begin{array}{l}\text { Activity: Icebreaker-Human Bingo } \\
\text { Homework: Complete three unselfish acts } \\
\text { of kindness each day for three different } \\
\text { people before next class. }\end{array}$ \\
\hline
\end{tabular}




\begin{tabular}{|c|c|c|c|}
\hline 2 & $\begin{array}{l}\text { Reflecting on } \\
\text { happiness }\end{array}$ & $\begin{array}{l}\text { Identify personal sources of } \\
\text { happiness. The difference } \\
\text { between happiness and } \\
\text { pleasure }\end{array}$ & $\begin{array}{l}\text { Activity: Photo voice- Each participant } \\
\text { provides photos that make them happy } \\
\text { Homework: Each morning, write down } 3 \\
\text { things that you have to look forward to } \\
\text { that day. Write down } 3 \text { things at the end } \\
\text { of the day that were good. }\end{array}$ \\
\hline 3 & $\begin{array}{l}\text { Compassion } \\
\& \text { human } \\
\text { connection }\end{array}$ & $\begin{array}{l}\text { Impact of compassion and } \\
\text { gratitude on happiness. The } \\
\text { importance of human } \\
\text { connection, intimacy, } \\
\text { vulnerability, and sharing }\end{array}$ & $\begin{array}{l}\text { Activity: Each day, write } 3 \text { things for which } \\
\text { you are grateful. } \\
\text { Homework: Hand-write a letter expressing } \\
\text { why someone is important to you }\end{array}$ \\
\hline 4 & $\begin{array}{l}\text { Stress } \\
\text { management }\end{array}$ & $\begin{array}{l}\text { Definition of stress, } \\
\text { individual causes of stress, , } \\
\text { and stress management } \\
\text { techniques. }\end{array}$ & $\begin{array}{l}\text { Activity: Therapy Puppies- therapy } \\
\text { puppies are brought in } \\
\text { Homework: Identify life stressors and } \\
\text { match which of Segal's } 5 \text { causes is creating } \\
\text { the stress. How can you restructure your } \\
\text { thinking to reduce your stress? }\end{array}$ \\
\hline 5 & Forgiveness & $\begin{array}{l}\text { Why being able to forgive is } \\
\text { crucial to one's happiness } \\
\text {. }\end{array}$ & $\begin{array}{l}\text { Activity: Group discussion on forgiveness } \\
\text { Homework: Write } 3 \text { letters: } \\
\text { 1. Write a letter apologizing to someone } \\
\text { who you treated unfairly (send) } \\
\text { 2. Write a letter of apology to yourself for } \\
\text { something you regret doing in the past } \\
\text { 3. Write a letter of forgiveness to } \\
\text { someone who has hurt you. (do not send } \\
\text { unless you want) }\end{array}$ \\
\hline 6 & $\begin{array}{l}\text { Transforming } \\
\text { suffering }\end{array}$ & $\begin{array}{l}\text { Dealing with guilt and } \\
\text { learning how our negative } \\
\text { experiences help us grow. }\end{array}$ & $\begin{array}{l}\text { Activity: Savoring- Participants were given } \\
\text { a Saltine cracker and asked to let the } \\
\text { cracker dissolve while noticing flavors that } \\
\text { go unnoticed when eaten quickly } \\
\text { Homework: Reflect on a negative } \\
\text { experience and identify how you have } \\
\text { grown from it. }\end{array}$ \\
\hline 7 & $\begin{array}{l}\text { Living in the } \\
\text { present/mind } \\
\text { fulness }\end{array}$ & $\begin{array}{l}\text { Mindfulness and how living } \\
\text { in the present can increase } \\
\text { happiness. }\end{array}$ & $\begin{array}{l}\text { Activity: Body scan- participants were led } \\
\text { through a meditation that brought their } \\
\text { attention to every part or their body. } \\
\text { Zen Garden- Create a Zen garden. } \\
\text { Homework: Practice mindfulness } \\
\text { throughout the week \& reflect in journal. }\end{array}$ \\
\hline 8 & $\begin{array}{l}\text { Humor \& } \\
\text { Closing }\end{array}$ & $\begin{array}{l}\text { How humor improves one's } \\
\text { wellbeing. Summary and } \\
\text { share those experiences } \\
\text { that were most helpful. }\end{array}$ & $\begin{array}{l}\text { Activity: Participants share funny } \\
\text { stories/jokes with the class }\end{array}$ \\
\hline
\end{tabular}


Participants completed a set of valid and reliable survey instruments before the first class session and then again after the conclusion of the program (after $8^{\text {th }}$ week). These instruments were administered to the participants after they signed the informed consent as required by our human subjects committee. The entire questionnaire took approximately 30 minutes to complete and subjects were asked to wait until everyone was done prior to submitting them to the researchers. Additionally, 6 months after completion of the program, participants were asked to return for a booster session. The purpose of holding the booster session was to discuss which lessons have continued to impact their daily lives and to assess the program's continued impact on participant subjective happiness, depressive symptoms, life satisfaction, stress levels, mindfulness, and overall mood. This questionnaire also contained additional open-ended questions including; 1 ) How do you define your happiness? Has your definition changed since taking the course? If so, how is it different? 2) What skills and practices that you learned from the class do you find yourself still using? 3) What are the biggest barriers you face to increasing your own happiness? 4) Do you notice any differences in your overall happiness levels after taking the class? 5) Looking back, is there a topic you wish would have been covered in the course that was not discussed? 6) Do you have any additional comments? Once all participants completed the survey instruments, the 90 minute, "booster" session was conducted.

\subsection{Statistical Analysis}

A repeated measures linear mixed effects model was used to examine changes in each outcome variable across the three study time points (pre-intervention, post-intervention and at the 6-month follow-up) accounting for the correlation between measures on the same subject by directly modeling the covariance structure of the residuals as unstructured. Model assumptions were assessed via graphical examination of the residuals. Tests for mean differences were conducted using the Kenward-Roger approximation for the degrees of freedom and $p$-values comparing the mean response between time points were adjusted for multiple comparisons using the Tukey-Kramer method. All statistical analyses were performed using SAS software, Version 9.4 (SAS Institute, Cary, NC).

\section{Results}

\subsection{Repeated Measures Linear Modeling}

After controlling for age, gender, and health issues, there was a significant time effect for happiness $(F=7.33 ; p<.01)$, mood state of tiredness $(F=18.95 ; p<0.0001)$, and mindfulness constructs of non-judging $(F=5.15 ; p<0.05)$ and non-reactivity $(F=3.74 ; p<0.05)$, stress $(F=8.73$; $p<.01)$, and SWL $(F=3.58 ; p<.05)$. There were non-significant effects for depression $(F=3.14 ; p=.06)$, Mood states of tension $(F=3.16 ; p=.06)$, calmness $(F=1.55 ; p=.23)$, and energetic $(F=.92 ; p=.41)$ (see Table 3). Post hoc pairwise comparisons were conducted between time points (post-pre, post- 6 months, and pre- 6 months) to examine the specific changes in the measures of interest (Table 4). These results showed that there were significant differences between pre-intervention and 6 months post program in happiness, mood construct of tiredness, and mindfulness aspects of non-judging and non- reactivity. The model adjusted means are displayed in Table 5. Examination of the means show that happiness increased from baseline $(4.82 \pm .33)$ to end of program $(5.47$ 
\pm .33 ) and then declined slightly at 6 months post program $(5.24 \pm .31)$. At 6 months, the level of happiness was still significantly greater than the baseline level. Similarly, mood aspect of tiredness was at its greatest at baseline $(13.01 \pm .62)$, declined at end of program $(9.43 \pm .83)$ and then slightly increased at 6 months after program completion $(10.49 \pm .90)$. However, that level at 6 months post- program remained significantly better than the baseline level of tiredness. The mindful aspect of non-judging steadily increased from baseline $(25.24 \pm 1.55)$ to post- program $(27.48 \pm 1.43)$ to 6 months $(28.15 \pm 1.56)$ as did the mindful aspect of non-reactivity from $20.39 \pm$ 1.03 at baseline to $21.98 \pm .93$ at post program to $23.64 \pm 1.13$ at 6 months. These are the model adjusted means and standard errors.

Table 3 Repeated Measures Mixed Effects Model.

\begin{tabular}{|c|c|c|c|c|c|}
\hline Variable & Effect & NumDF & DenDF & FValue & ProbF \\
\hline \multirow{4}{*}{$\begin{array}{l}\text { Subjective } \\
\text { Happiness }\end{array}$} & Time & 2 & 26.01 & 7.33 & 0.0030 \\
\hline & Gender & 1 & 28.65 & 0.13 & 0.7212 \\
\hline & Age & 1 & 30.63 & 0.05 & 0.8321 \\
\hline & Health concerns & 1 & 29.57 & 1.92 & 0.1766 \\
\hline \multirow{4}{*}{$\begin{array}{l}\text { ADACL: } \\
\text { Tiredness }\end{array}$} & Time & 2 & 22.94 & 18.95 & 0.0000 \\
\hline & Gender & 1 & 28.41 & 0.29 & 0.5918 \\
\hline & Age & 1 & 28.80 & 0.23 & 0.6353 \\
\hline & Health concerns & 1 & 28.62 & 0.94 & 0.3392 \\
\hline \multirow{4}{*}{$\begin{array}{l}\text { Mindfulness: } \\
\text { Nonjudging }\end{array}$} & Time & 2 & 22.15 & 5.15 & 0.0146 \\
\hline & Gender & 1 & 32.35 & 1.51 & 0.2279 \\
\hline & Age & 1 & 30.36 & 0.03 & 0.8691 \\
\hline & Health concerns & 1 & 30.30 & 0.44 & 0.5114 \\
\hline \multirow{4}{*}{$\begin{array}{l}\text { Mindfulness: } \\
\text { Nonreactivity }\end{array}$} & Time & 2 & 18.97 & 3.74 & 0.0428 \\
\hline & Gender & 1 & 18.62 & 0.32 & 0.5804 \\
\hline & Age & 1 & 23.37 & 0.26 & 0.6179 \\
\hline & Health concerns & 1 & 20.47 & 1.23 & 0.2803 \\
\hline
\end{tabular}


Table 4 Comparisons between time points.

\begin{tabular}{|c|c|c|c|c|c|c|c|}
\hline Variable & $\begin{array}{l}\text { Time Point } \\
\text { Comparison }\end{array}$ & $\begin{array}{l}\text { Mean } \\
\text { Difference }\end{array}$ & $\begin{array}{l}\text { Standard } \\
\text { Error }\end{array}$ & $\begin{array}{l}K-R \\
D F\end{array}$ & T Value & $\begin{array}{l}\text { Unadjusted } \\
\mathrm{p} \text {-value }\end{array}$ & $\begin{array}{l}\text { Tukey- } \\
\text { Kramer } \\
\text { p-value }\end{array}$ \\
\hline \multirow{3}{*}{$\begin{array}{l}\text { Subjective } \\
\text { Happiness }\end{array}$} & 6 months - post & -0.23 & 0.15 & 21.8 & -1.46 & 0.1587 & 0.3294 \\
\hline & 6 months - pre & 0.42 & 0.20 & 28.7 & 2.09 & 0.0455 & 0.1095 \\
\hline & post-pre & 0.65 & 0.17 & 32.1 & 3.85 & 0.0005 & 0.0015 \\
\hline \multirow{3}{*}{ ADACL: Tiredness } & 6 months - post & 1.06 & 0.62 & 21.2 & 1.72 & 0.1001 & 0.2213 \\
\hline & 6 months - pre & -2.52 & 0.72 & 21.1 & -3.51 & 0.0021 & 0.0056 \\
\hline & post - pre & -3.58 & 0.57 & 30.8 & -6.29 & 0.0000 & 0.0000 \\
\hline \multirow{3}{*}{$\begin{array}{l}\text { Mindfulness: } \\
\text { Nonjudging }\end{array}$} & 6 months - post & 0.66 & 0.92 & 21.6 & 0.72 & 0.4811 & 0.7563 \\
\hline & 6 months - pre & 2.91 & 0.90 & 20.3 & 3.21 & 0.0043 & 0.0114 \\
\hline & post-pre & 2.24 & 0.99 & 31.5 & 2.27 & 0.0301 & 0.0749 \\
\hline \multirow{3}{*}{$\begin{array}{l}\text { Mindfulness: } \\
\text { Nonreactivity }\end{array}$} & 6 months - post & 1.66 & 0.95 & 19.9 & 1.74 & 0.0968 & 0.2144 \\
\hline & 6 months - pre & 3.24 & 1.18 & 13.9 & 2.75 & 0.0159 & 0.0395 \\
\hline & post-pre & 1.58 & 0.75 & 27.8 & 2.11 & 0.0441 & 0.1063 \\
\hline
\end{tabular}


Table 5 Model means by time point.

\begin{tabular}{cccccc}
\hline & & & \multicolumn{3}{c}{ Lower } \\
Variable & Time & & Standard & $95 \%$ & Upper \\
& Point & Mean & Error & $\mathrm{Cl}$ & $95 \% \mathrm{Cl}$ \\
\hline \multirow{2}{*}{$\begin{array}{c}\text { Subjective } \\
\text { Happiness }\end{array}$} & 6 months & 5.24 & 0.31 & 4.60 & 5.88 \\
\cline { 2 - 6 } & post & 5.47 & 0.33 & 4.81 & 6.13 \\
\cline { 2 - 6 } & pre & 4.82 & 0.33 & 4.15 & 5.49 \\
\hline \multirow{2}{*}{$\begin{array}{c}\text { ADACL: } \\
\text { Tiredness }\end{array}$} & post & 9.43 & 0.83 & 7.76 & 11.11 \\
\cline { 2 - 6 } & pre & 13.01 & 0.62 & 11.74 & 14.28 \\
\hline \multirow{2}{*}{$\begin{array}{c}\text { Mindfulness: } \\
\text { Non-judging }\end{array}$} & post & 27.48 & 1.43 & 24.58 & 30.39 \\
\cline { 2 - 6 } & pre & 25.24 & 1.55 & 22.11 & 28.37 \\
\hline \multirow{2}{*}{$\begin{array}{c}\text { Mindfulness: } \\
\text { Non- }\end{array}$} & 6 months & 23.64 & 1.13 & 21.31 & 25.97 \\
\cline { 2 - 6 } reactivity & post & 21.98 & 0.93 & 20.07 & 23.88 \\
\cline { 2 - 6 } & pre & 20.39 & 1.03 & 18.30 & 22.49
\end{tabular}

\section{Discussion}

The aim of this study was to examine if the immediate positive impact an intervention had on increasing the happiness of older adults would be sustained over a 6 month period. Self-reported levels of happiness and mindfulness did remain significantly higher than baseline. The topics of defining happiness and reflecting on happiness, stress management, compassion and human connection, forgiveness, mindfulness, and humor were apparently meaningful to the participants and presented in a manner so that they continued applying the lessons to their life after the course was completed. These lessons impacted the older adults in ways that promoted a sense of positive well-being. This is an important concept as happiness has been said to be closely related to life satisfaction, appreciation of life, and moments of pleasure [25]. When participants of the study were asked to define happiness, they mentioned words such as being content, joy, wellbeing, peace, and faith. One participant stated "It is a quiet feeling of joy that I feel behind the eyes and the feeling of well-being ...." Another mentioned, "A state of mind, attitude, being positive, avoiding negativity". These simple concepts of seeking positive experiences while avoiding negative ones has been identified by the Dalai Lama as being fundamental to one's happiness.

The notion that one's level of happiness can be improved and then maintained is an important finding, specifically in the older adult population as they are at higher risk of disease associated with negative psychological states. Happiness related studies have been shown to have a positive 
impact on heart health $[26,27]$ and reduce disease and disability [29]. Furthermore, longitudinal studies have indicated that those with higher levels of happiness tend to live longer [30,31].

One finding worth noting is the impact this program had on depression. Although there was not a significant effect of time $(p=.06)$ there was a significant difference immediately post intervention $(p<0.01 ;$ pre $=15.39 \pm 1.19$, post $=13.09 \pm 0.89)$. This indicates it may be beneficial to provide more booster sessions or skills the participants can develop and employ in their daily lives. It may also be beneficial to send emails reminding them to redo one of the assignments or provide a new assignment for them to apply to their lives. However, it was encouraging to see the levels of selfreported depression were highest at the pre-test $(15.39 \pm 1.19)$, fell at post-test $(13.09 \pm .82)$ and then rose slightly $(13.95 \pm 1.12)$. However, the depression scores are still below the pre-test level. These levels all fall within the category of mild depression [49]. The aim was not to reduce depression, but seeing this decline in self-reported depression scores during the course of the study with an associated increase in happiness scores is worthy of further study.

The significant time effect for the two identified aspects of mindfulness (non-react and nonjudge) is not surprising as the course emphasized learning how to respond to circumstances in a non-judgmental and positive manner. Additionally, we believe it is possible that participants became more mindful since mindfulness has gained a great deal of attention in the media in recent years. Due to this, participants have likely paid more attention to reports. This attention may serve as reminders to the participants and help them continue the practices they developed during the course. It may also be that by becoming more aware of one's thoughts through participation in the various lectures, discussions, and activities, the older adults in this study became more mindful. When asked about the strategies they continue to use many mentioned mindfulness techniques, changing perspectives about a situation, and purposively thinking to be more positive. This is evident by some of the thoughts expressed by the participants. For example, one of the participants discussed how just being present while washing their hands has helped them learn to be more present throughout their day. One of the directors has also indicated how she has observed people at the center are being more open to discussion and less judgmental.

Other participants provided examples of non-judging $(p<.05)$ or non-reactivity $(p<.05)$ with one discussing how they have learned to stop when they recognize they are starting to feel frustrated and then realize they have the power to change that emotion. Another participant stated how they used to feel they were less happy than most other people; however, now they recognize that it is all about how they are perceiving things and they now have the power to change those perceptions.

One of the center directors mentioned that she has heard participants in the class use language and techniques learned from the Art of Happiness and they have encouraged others to take a moment to think about what just happened and take a moment before reacting to it. This director, who is very involved in her center, has observed this type of discussion which indicates continued application of the principles taught in the course still being applied in their daily lives.

Another potential outcome of the program could be related to having built a better sense of community. The participants in the class became close with each other through sharing their experiences and thoughts on the various topics. This may have expanded to others in the senior center community. One of the senior center directors observed that they noticed how those in the class were having an impact on the overall environment of the center and had been discussing the lessons with others who had not chosen to be part of the class. She felt that these lessons were 
therefore being learned by many at the center and not just those who attended the classes. This may have helped to increase social connections in the older adults, which is an important component for their happiness [53].

There was a statistically significant effect of time on the negative affect of mood, tiredness. We know the literature suggests positive affect is associated with happiness [25] so is it possible decreases in negative affect such as tiredness may be linked to an increase in happiness. The negative mood affect of tiredness may also be more prevalent in these older adults. It is possible that being happy could decrease this negative mood affect.

Further, while forgiveness was not measured as a construct, it can have a large impact on one's happiness $[2,54,55]$. An example of this was shared by one of the directors. She shared that after one of the participants wrote a letter of forgiveness to her sister who lives over 1500 miles away and to whom she had not spoken in over 35 years was able to reconnect. They are now communicating and much happier to have put this past behind them.

The major limitation of this study is there was not a randomized control trial and there was no attempt to compare to a control group of independently living older adults. This program was also conducted in senior centers, which are community centers for older adults and was a quasiexperimental study. Therefore, further researched is needed to test the widespread implementation in senior center /community center settings. Additionally, we did not measure the impact that this program may have had on the participants in the senior center via social support or simply meeting in groups for lecture, discussions, and activities. Although we did recruit from two different senior centers in ethnically diverse communities, this sample was not ethnically diverse and was primarily comprised of females so it is difficult to generalize the findings to older adult males or other ethnic populations. Lastly, while Buddhist philosophy was a basis for some of the activities and discussions only traditional Western concepts were measured.

\section{Conclusions}

This study shows promise in the course being able to have some long-term impact on older adult's perceptions and psychological health and well-being. Of course, it also demonstrated how important booster sessions and reminders are to create long term behavior change. Changing how older adults react to situations, stressors, and their perception of things is similar to trying to impact any other aspect of their life such as diet or exercise. Habits do not change easily and once that daily reminder is removed people tend to gravitate back to the way they have always been. As the saying goes, "use it or lose it". This was apparent in this study as some of the measures that were significant immediately after the course were not significant 6 months later. We would like to add other follow-ups to the intervention where participants will receive weekly reminders, activities (new and old), and an opportunity to ask questions of the researchers.

The course also seemed to have help develop a positive sense of community thereby making the center an attractive place that may encourage greater membership. The success of the course further illustrates how neuroplasticity in older adults is still there and we can continue to learn throughout our healthy life. This also demonstrates the potential for positive reception of positive psychology programs in a population of older adults. It may be that focusing on positive aspects of mental well-being is a better avenue to approach mental health in a population of older adults who are often faced with life events or situations which can impact them. With proper training 
and facilitation, the "Art of Happiness" is one program that can be effectively implemented in any community center. We believe this approach can be effective across cultures, religious, gender, and ethnic groups. Further research is needed to bear this out, but the current findings show promise.

\section{Acknowledgments}

We would like to acknowledge the staff and members of Howard Weston Senior Center and Claymore Senior Center.

\section{Author Contributions}

Orsega-Smith performed the initial analysis and wrote the drafts of the paper; Goodwin conceptualized the study and wrote the discussion; Turner, Greenawalt, \& Rathie conducted the intervention at the senior center. They also assisted in writing the introduction; Ziegler completed the final analysis.

\section{Funding}

University of Delaware Summer Service Learning partially funded this project.

\section{Competing Interests}

The authors have declared that no competing interests exist.

\section{References}

1. Lama D, Cutler HC. The Art of Happiness: A handbook for living. New York; Riverhead Books. 1998.

2. Lyubomirsky S. The how of happiness: A scientific approach to getting the life you want. New York: The Penguin Press; 2008 (p.20-22).

3. Turner J, Greenawalt K, Goodwin S, Rathie E, Orsega-Smith E. The development and implementation of the art of happiness intervention for community dwelling older adults. $J$ Educ Gerontol. 2017; 42: 630-640.

4. Administration on Aging, U.S. Department of Health \& Human Services. A Profile of Older Americans: 2015. 2015.

5. Centers for Disease Control and Prevention. The State of Aging and Health in America 2013. Retrievedfrom

http://www.cdc.gov/features/agingandhealth/State_of_aging_and_health_in_america_2013. pdf

6. Baird BM, Lucas RE, Donnellan MB. Life satisfaction across the lifespan: Findings from two nationally representative panel studies. Soc Indic Res. 2010; 99: 183-203.

7. Bonhote K, Romano-Egan J, Cornwell C. Altruism and creative expression in a long-term older adult psychotherapy group. Issues Ment Health Nurs. 1999; 20: 603-617.

8. Shapira N, Barak A, Gal I. Promoting older adults' well-being through Internet training and use. Aging Ment Health. 2007; 11: 477-484. 
9. Shtompel N, Whiteman K, Ruggiano N. Negative feelings and help seeking among older adults with chronic conditions. J Gerontol Soc Work. 2014; 57: 810-824.

10. Steptoe A, Deaton A, Stone AA. Subjective wellbeing, health, and ageing. The Lancet. 2015; 385: 640-648.

11. Corcoran J, Brown E, Davis M, Pineda M, Kadolph J, Bell H. Depression in older adults: a metasynthesis. J Gerontol Soc Work. 2013; 56: 509-534.

12. Centers for Disease Control and Prevention and National Association of Chronic Disease. The State of Mental Health and Aging in America Issue Brief 1: What Do the Data Tell Us? Atlanta, GA. 2008.

13. Blazer DG. Depression in late life: review and commentary. J Gerontol A Biol Sci Med Sci. 2003; 58: 249-265.

14. National Council on Aging. Higher tier evidence -based health promotion/disease prevention programs. 2017. Retrieved from: https://www.ncoa.org/resources/ebpchart/.

15. Baltes PB, Baltes MM. Psychological perspectives on successful aging: The model of selective optimization with compensation. Successful Aging: Perspectives from the Behavioral Sciences. 1990; 1: 1-34.

16. Duckworth AL, Steen TA, Seligman ME. Positive psychology in clinical practice. Ann Rev Clin Psychol. 2005; 1: 629-651.

17. Friedman E, Ruini C, Foy R, Jaros L, Sampson H, Ryff C. Lighten UP! A community -based group intervention to promote psychological well-being in older adults. Aging Ment Health. 2017; 21: 199-205.

18. Wood AM, Tarrier N. Positive clinical psychology: a new vision and strategy for integrated research and practice. Clin Psychol Rev. 2010; 30: 819-829.

19. Sutipan $P$, Intarakamhang $U$, Macaskill $A$. The impact of a positive psychological interventions on well-being in healthy elderly people. J Happiness Stud. 2017; 18: 269-291.

20. Seligman ME, Csikszentmihalyi M. Positive psychology. Am Psychol. 2000; 1: 5-183.

21. Oddone CG, Hybels CF, McQuoid DR, Steffens DC. Social support modifies the relationship between personality and depressive symptoms in older adults. Am J Geriatr Psychiat. 2011; 19: 123-131.

22. Seligman ME, Steen TA, Park N, Peterson C. Positive psychology progress: empirical validation of interventions. Am Psychol. 2005; 60: 410-421.

23. Kim ES, Park N, Peterson C. Dispositional optimism protects older adults from stroke: The health and retirement study. Stroke. 2011; 42: 2855-2859.

24. Ho HC, Yeung DY, Kwok SY. Development and evaluation of the positive psychology intervention for older adults. J Positive Psychol. 2014; 9: 187-197.

25. Lyubomirsky S, King L, Diener E. The benefits of frequent positive affect: Does happiness lead to success? Psychol Bull. 2005; 131: 803-855.

26. Davidson KW, Mostofsky E, Whang W. Don't worry, be happy: positive affect and reduced 10year incident coronary heart disease: The Canadian Nova Scotia Health Survey. Eur Heart J. 2010; 31: 1065-1070.

27. Steptoe A, Wardle J, Marmot M. Positive affect and health-related neuroendocrine, cardiovascular, and inflammatory processes. P Natl Acad Sci USA. 2005; 102: 6508-6512.

28. Cohen S, Doyle WJ, Turner R, Alper CM, Skoner DP. Sociability and susceptibility to the common cold. Psychol Sci. 2003; 14: 389-395. 
29. Ostir GV, Markides KS, Peek MK, Goodwin JS. The association between emotional well-being and the incidence of stroke in older adults. Psychosom Med. 2001; 63: 210-215.

30. Danner DD, Snowdon DA, Friesen WV. Positive emotions in early life and longevity: findings from the nun study. J Personality Soc Psychol. 2001; 80: 804.

31. Steptoe A, Wardle J. Positive affect measured using ecological momentary assessment and survival in older men and women. P Natl Acad Sci. 2011; 108: 18244-18248.

32. Zautra AJ, Johnson LM, Davis MC. Positive affect as a source of resilience for women in chronic pain. J Consulting Clin Psychol. 2005; 73: 212.

33. Kabat-Zinn J. Coming to our senses: Healing ourselves and the world through mindfulness. United Kingdom: Hachette Publishers; 2005.

34. Foulk MA, Ingersoll-Dayton B, Kavanagh J, Robinson E, Kales HC. Mindfulness-based cognitive therapy with older adults: An exploratory study. J Gerontol Soc Work. 2014; 57: 498-520.

35. Morone NE, Lynch CS, Greco CM, Tindle HA, Weiner DK. "I felt like a new person." The effects of mindfulness meditation on older adults with chronic pain: qualitative narrative analysis of diary entries. J Pain. 2008; 9: 841-848.

36. Carter C, Forgive and Feel Happier, May 12, 2008. Available from: https://greatergood.berkeley.edu/article/item/forgive_andfeel_happier. Accessed August 29, 2018.

37. Leung A, Kier C, Fung T, Fung L, Sproule R. Searching for happiness: The importance of social capital. In: Delle Fave A. (eds) The exploration of happiness. Happiness studies book series. Dordrecht: Springer, 2013 (p.247-267).

38. Amado-Boccara I, Donnet D, Olie JP. Conception of mood in psychology. Encephale. 1993; 19: 117-122.

39. Watson D, Clark LA, Tellegen A. Development and validation of brief measures of positive and negative affect: the PANAS scales. J Personality Soc Psychol. 1988; 54: 1063-1070.

40. Clark LA, Watson D, Leeka J. Diurnal variation in the positive affects. Motivation Emot.1989; 13: 205-234.

41. Berry DS, Hansen JS. Positive affect, negative affect, and social interaction. J Personality Soc Psychol.1996; 71: 796-809.

42. Seligman ME. Flourish: A visionary new understanding of happiness and well-being. New York: Simon and Schuster; 2012.

43. Lyubomirsky S, Lepper HS. A measure of subjective happiness: Preliminary reliability and construct validation. Soc Indic Res. 1999; 46: 137-155.

44. Baer RA, Smith GT, Hopkins J, Krietemeyer J, Toney L. Using self- report assessment methods to explore facets of mindfulness. Assessment. 2006; 13: 27- 45.

45. Diener ED, Emmons RA, Larsen RJ, Griffin S. The satisfaction with life scale. J Personality Assess. 1985; 49: 71-75.

46. Pavot W, Diener E. The satisfaction with life scale and the emerging construct of life satisfaction. J Positive Psychol. 2008; 3: 137-152.

47. Thayer RE. Measurement of activation through self-report. Psychol Rep. 1967; 20: 663-678.

48. Thayer RE. The biopsychology of mood and arousal, New York: Oxford University Press. 1989.

49. Cohen S, Kamarck T, Mermelstein R. A global measure of perceived stress. J Health Soc Behav. 1983; 4: 385-396. 
50. Lee EH. Review of the psychometric evidence of the perceived stress scale. Asian Nurs Res. 2012; 6: 121-127.

51. Kroenke K, Strine TW, Spitzer RL, Williams JB, Berry JT, Mokdad AH. The PHQ-8 as a measure of current depression in the general population. J Affect Disorders. 2009; 114: 163-173.

52. Arroll B, Goodyear-Smith F, Crengle S, Gunn J, Ngaire K, Fishman T, et al. Validation of PHQ-2 and $\mathrm{PHQ}-9$ to screen for major depression in the primary care population. Ann Fam Med. 2010; 8: 348-353.

53. Fowler JH, Christakis NA. Dynamic spread of happiness in a large social network: longitudinal analysis over 20 years in the Framingham Heart Study. Brit Med J. 2008; 337: a2338. https://doi.org/10.1136/bmj.a2338.

54. Chan DW. Subjective well-being of Hong Kong Chinese teachers: The contribution of gratitude, forgiveness, and the orientations to happiness. Teach Teach Educ. 2013; 32: 22-30.

55. Maltby J, Day L, Barber L. Forgiveness and happiness. The differing contexts of forgiveness using the distinction between hedonic and eudaimonic happiness. J Happiness Stud. 2005; 6: $1-13$.

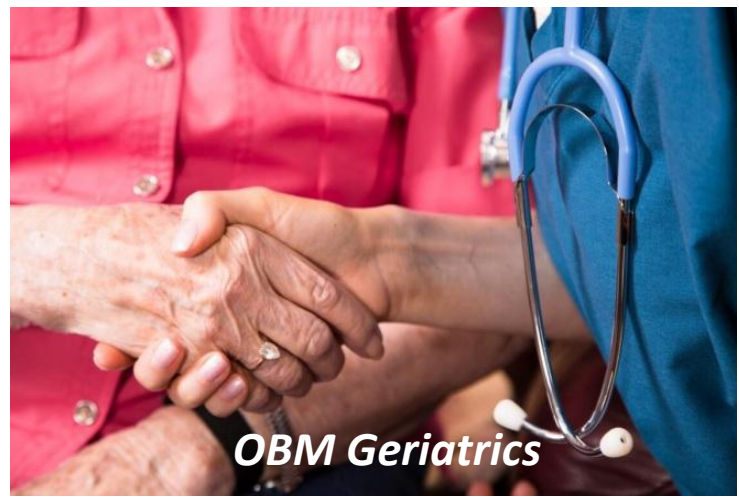

Enjoy OBM Geriatrics by:

1. Submitting a manuscript

2. Joining in volunteer reviewer bank

3. Joining Editorial Board

4. Guest editing a special issue

For more details, please visit: http://www.lidsen.com/journals/geriatrics 